\title{
Efficacy of intravenous procainamide infusion in converting atrial fibrillation to sinus rhythm Relation to left atrial size
}

\author{
STEPHEN W HALPERN, GRAY ELLRODT, BRAMAH N SINGH, \\ WILLIAM J MANDEL
}

From the Division of Cardiology, Department of Medicine, Cedars-Sinai Medical Center, and the UCLA School of Medicine, Los Angeles, California, USA

SUMmary The efficacy of intravenous procainamide, infused at $30 \mathrm{mg} / \mathrm{min}$ to a maximum dose of $20 \mathrm{mg} / \mathrm{kg}$, in converting atrial fibrillation was evaluated under electrocardiographic and blood pressure control in 21 patients. Nine patients had atherosclerotic heart disease, seven had valvular lesions, five had hypertension, and six had no apparent heart disease. Nine patients (converters), who reverted to sinus rhythm at a mean dose of procainamide of $13.3 \pm 3.6 \mathrm{mg} / \mathrm{kg}$ (mean plasma concentration, $7.4 \pm 3.9 \mu \mathrm{g} / \mathrm{ml}$ ) had normal echocardiographic left atrial diameters. All but one of the remainder, the 12 non-converters, who received a mean drug dose of $13.1 \pm 3.5 \mathrm{mg} / \mathrm{kg}$ (mean plasma concentration $13.9 \pm 7.6 \mu \mathrm{g} / \mathrm{ml}$ ), had atrial diameters exceeding $4.0 \mathrm{~cm}$. QRS and QTc intervals were not altered significantly in converters, but were prolonged significantly in non-converters. No serious side effects from the infusion were encountered. Intravenous procainamide infusion appears to be a safe and rapidly effective method of converting recent-onset atrial fibrillation to sinus rhythm in patients with normal left atrial dimensions.

Atrial fibrillation associated with acute haemodynamic deterioration is often best controlled by immediate direct current countershock. If the clinical situation does not constitute an emergency, however, the ventricular response may be controlled first by digoxin or propranolol, and elective cardioversion attempted subsequently, either using oral quinidine or electroversion. Neither approach is universally applicable. A method using brief intravenous infusion of an antifibrillatory drug, if effective and safe, is simpler and preferable to electrical defibrillation or to conversion after prolonged oral drug administration. Procainamide, in spite of its pharmacological similarities to quinidine, ${ }^{1-3}$ has been used little for this purpose.

Both quinidine and procainamide are membranestabilising or class I drugs. ${ }^{134}$ Both also prolong the effective refractory period and raise the threshold of excitability without changing the resting membrane voltage. ${ }^{35}$ It is, therefore, not unreasonable to expect procainamide to be at least as effective as quinidine in converting atrial fibrillation to normal sinus rhythm, with the added advantage of greater Received for publication 3 June 1980 flexibility of parenteral administration because of lower toxicity.

While the effectiveness of procainamide in the control of ventricular arrhythmias is well documented, there is little information about its effect on atrial arrhythmias. Preliminary data from this institution suggested that the rapidity of conversion with procainamide compared favourably with that of direct current countershock without the attendant problems of the latter. We assessed the effects of procainamide infusion on the rapid conversion of atrial fibrillation, with particular reference to left atrial size.

\section{Patients and methods}

Twenty-one patients, 12 men and nine women, aged 27 to 84 years (mean, 63 years), with new or paroxysmal atrial fibrillation, were studied (Table 1). The following patients were excluded: (1) those already receiving procainamide; (2) those having known toxicity or hypersensitivity to procainamide; (3) those having advanced (second or third degree) atrioventricular block; or (4) those having received 
digitalis within the preceding six hours. Procainamide in a concentration of $30 \mathrm{mg} / \mathrm{ml}$ dissolved in 5 per cent dextrose in water, was infused at a rate of $30 \mathrm{mg} / \mathrm{min}$ to one of several end-points: (1) maximum dose, arbitrarily defined as $20 \mathrm{mg} / \mathrm{kg}$; (2) conversion to normal sinus rhythm; (3) hypotension, defined as greater than a 20 per cent fall in systolic blood pressure; (4) QRS or QTc prolongation to greater than 130 per cent of control; or (5) development of second or third degree atrioventricular block.

A baseline 12 lead electrocardiogram, 60-second lead II rhythm strip, and supine blood pressure were recorded just before the start of drug infusion.
Cuff blood pressure was determined every three minutes throughout the infusion period and at fiveminute intervals until stabilisation thereafter. Continuous monitoring and data storage of lead II throughout the infusion period was done in six patients using a Wolff MR-41CD physiological tape recorder interfaced with a Hewlett-Packard Model no. 78303A 4-channel oscilloscope. In the others, 15 -second rhythm strips at $25 \mathrm{~mm} / \mathrm{s}$ paper speed were obtained during each minute of infusion. The ventricular rate at the end of each minute of infusion was determined by averaging 15 cardiac cycles. No attempt was made to record the atrial fibrillatory rate from the surface tracings because

Table 1 Clinical features of patients with atrial fibrillation treated with procainamide

\begin{tabular}{|c|c|c|c|c|c|c|c|c|c|}
\hline \multirow[b]{2}{*}{$\begin{array}{l}\text { Case } \\
\text { no. }\end{array}$} & \multirow[b]{2}{*}{$\underset{(y)}{\operatorname{Age}}$} & \multirow[b]{2}{*}{ Sex } & \multicolumn{7}{|l|}{ Atrial fibrillation } \\
\hline & & & Suspected aetiology & Duration & $\begin{array}{l}\text { Blood } \\
\text { pressure } \\
\text { (initial, } \\
\text { mmHg) }\end{array}$ & $\begin{array}{l}\text { Ventricular } \\
\text { rate } \\
\text { (initial, } \\
\text { beats } / \text { min) }\end{array}$ & NYHA & Associated diagnosis & $\begin{array}{l}\text { Previous } \\
\text { history }\end{array}$ \\
\hline \multicolumn{10}{|c|}{ (A) Converters (CV) } \\
\hline $\begin{array}{l}1 \\
2\end{array}$ & $\begin{array}{l}70 \\
40\end{array}$ & $M$ & Idiopathic & $4 \mathrm{~h}$ & $130 / 100$ & 130 & $\begin{array}{l}0 \\
0\end{array}$ & & Palpitation \\
\hline 3 & 51 & $\begin{array}{l}M \\
M\end{array}$ & $\begin{array}{l}\text { Hypertension } \\
\text { Idiopathic }\end{array}$ & $\begin{array}{l}1 \mathrm{~d} \\
1 \mathrm{~d}\end{array}$ & $\begin{array}{l}120 / 90 \\
120 / 80\end{array}$ & $\begin{array}{l}158 \\
100\end{array}$ & $\begin{array}{l}\mathbf{0} \\
\mathbf{0}\end{array}$ & & $\begin{array}{l}\text { Atrial } \\
\text { fibrillation }\end{array}$ \\
\hline 4 & 84 & $\mathbf{F}$ & Atherosclerotic heart disease & $1 \mathrm{~d}$ & $90 / 70$ & 160 & $\mathbf{I}$ & \multicolumn{2}{|c|}{$\begin{array}{l}\text { LBBB, acute pancreatitis, } \\
\text { septicaemia }\end{array}$} \\
\hline $\begin{array}{l}5 \\
6\end{array}$ & $\begin{array}{l}57 \\
65\end{array}$ & $\begin{array}{l}\mathrm{F} \\
\mathbf{M}\end{array}$ & $\begin{array}{l}\text { Idiopathic } \\
\text { Hypertension, atherosclerotic } \\
\text { heart disease }\end{array}$ & $\begin{array}{l}6 \mathrm{~h} \\
7 \mathrm{~h}\end{array}$ & $\begin{array}{l}118 / 68 \\
142 / 100\end{array}$ & $\begin{array}{l}164 \\
110\end{array}$ & $\begin{array}{l}\mathbf{0} \\
\mathbf{I}\end{array}$ & Hypothyroidism & $\begin{array}{l}\text { Palpitat ion } \\
\text { Palpitation }\end{array}$ \\
\hline 7 & 62 & $\mathbf{M}$ & Atherosclerotic heart disease & $<24 \mathrm{~h}$ & $103 / 50$ & 130 & II & \multirow{3}{*}{$\begin{array}{l}\text { PUO } \\
\text { Acute myocardial } \\
\text { infarction }\end{array}$} & $\begin{array}{l}\text { Atrial } \\
\text { fibrillation }\end{array}$ \\
\hline 8 & 51 & $\mathbf{M}$ & $\begin{array}{l}\text { Atherosclerotic heart disease, } \\
\text { aortic valve disease (stenosis } \\
\text { and regurgitation) }\end{array}$ & $2 \mathrm{~h}$ & $108 / 74$ & 100 & $\mathbf{I}$ & & \\
\hline 9 & 27 & $\mathbf{M}$ & Idiopathic & $3 \mathrm{~h}$ & $108 / 75$ & 107 & 0 & & \\
\hline \multirow{2}{*}{$\begin{array}{l}(B) \\
10\end{array}$} & Non-con & iverters & $(\mathrm{NCV})$ & & & & & \multirow[b]{2}{*}{ Myxoedema } & \multirow{4}{*}{ Palpitation } \\
\hline & 72 & M & $\begin{array}{l}\text { Atherosclerotic heart disease, } \\
\text { mitral valve prolapse }\end{array}$ & $1 \mathrm{~d}$ & $150 / 90$ & 100 & 0 & & \\
\hline 11 & 40 & $\mathbf{F}$ & $\begin{array}{l}\text { Mitral regurgitation, aortic } \\
\text { regurgitation }\end{array}$ & $2 \mathrm{~d}$ & $120 / 90$ & 158 & $\mathbf{I}$ & \multirow{2}{*}{$\begin{array}{l}\text { Marfan's disease } \\
\text { Chronic obstructive } \\
\text { pulmonary disease, } \\
\text { pulmonary embolus }\end{array}$} & \\
\hline 12 & 78 & $\mathbf{F}$ & $\begin{array}{l}\text { Hypertension, atherosclerotic } \\
\text { heart disease }\end{array}$ & $1 \mathrm{~d}$ & $108 / 64$ & 110 & II & & \\
\hline $\begin{array}{l}13 \\
14\end{array}$ & $\begin{array}{l}77 \\
71\end{array}$ & $\begin{array}{l}\mathbf{M} \\
\mathbf{F}\end{array}$ & $\begin{array}{l}\text { Atherosclerotic heart disease } \\
\text { Idiopathic }\end{array}$ & $\begin{aligned} 1 \mathrm{~d} \\
30 \mathrm{~h}\end{aligned}$ & $\begin{array}{l}103 / 50 \\
116 / 72\end{array}$ & $\begin{array}{r}98 \\
125\end{array}$ & $\begin{array}{l}\text { I } \\
\mathbf{0}\end{array}$ & \multirow[t]{2}{*}{ Diabetes mellitus, obesity } & Palpitation \\
\hline 15 & 71 & $\mathbf{F}$ & $\begin{array}{l}\text { Hypertension, atherosclerotic } \\
\text { heart disease }\end{array}$ & 3 mth & $176 / 120$ & 70 & 0 & & Fatpitauoni \\
\hline 16 & 79 & $\mathbf{F}$ & Idiopathic & $1 \mathrm{~h}$ & $148 / 57$ & 170 & I & \multirow[t]{2}{*}{$\begin{array}{l}\text { Lymphoma, congestive } \\
\text { heart failure, pneumonia }\end{array}$} & \\
\hline 17 & 50 & $\mathbf{M}$ & $\begin{array}{l}\text { Rheumatic heart disease (mitral } \\
\text { stenosis and regurgitation) }\end{array}$ & $5 \mathrm{~d}$ & $126 / 70$ & 114 & $\mathbf{I}$ & & \\
\hline 18 & 66 & $\mathbf{F}$ & $\begin{array}{l}\text { Rheumatic heart disease (mitral } \\
\text { stenosis) }\end{array}$ & $5 \mathrm{~h}$ & $160 / 90$ & 129 & 0 & Hypothyroidism & \\
\hline \multirow[t]{2}{*}{19} & 70 & $\mathbf{F}$ & $\begin{array}{l}\text { Rheumatic heart disease (mitral } \\
\text { stenosis and regurgitation) }\end{array}$ & $19 \mathrm{~d}$ & $130 / 92$ & 140 & 0 & Atrial fibrillation & Palpitation \\
\hline & 0 & $\mathbf{M}$ & $\begin{array}{l}\text { Atherosclerotic heart disease, } \\
\text { hypertension }\end{array}$ & $1 \mathrm{~d}$ & $150 / 90$ & 100 & 0 & \multirow[t]{3}{*}{$\begin{array}{l}\text { Chronic renal failure, } \\
\text { congestive heart failure }\end{array}$} & \multirow{3}{*}{$\begin{array}{l}\text { Atrial } \\
\text { fibrillation, } \\
\text { PAT } \\
\text { Atrial } \\
\text { fibrillation }\end{array}$} \\
\hline 21 & 53 & $\mathbf{M}$ & $\begin{array}{l}\text { Rheumatic heart disease (mitral } \\
\text { regurgitation) }\end{array}$ & $4 \mathrm{~d}$ & $160 / 80$ & 73 & $\mathbf{I}$ & & \\
\hline Mean & $\begin{array}{l} \pm \mathrm{SD} \\
\text { ue }(\mathrm{CV} \mathrm{v}\end{array}$ & $\begin{array}{r}\mathrm{CV} \\
\mathrm{NCV} \\
\text { rs NCV) }\end{array}$ & $\begin{array}{ll}56 \pm 18 \\
y & 68 \pm 14 \\
\text { NS }\end{array}$ & $\begin{array}{l}115 \pm 15 \\
137 \pm 22 \\
<0.05\end{array}$ & $\begin{array}{l}5 / 79 \pm 18 \\
4 / 80 \pm 21 \\
<0.05 / \mathrm{NS}\end{array}$ & $\begin{array}{l}129 \pm 27 \\
116 \pm 31 \\
\text { NS }\end{array}$ & & & \\
\hline
\end{tabular}

NYHA, New York Heart Association classification; LBBB, left bundle-branch block; PUO, pyrexia of unknown origin; PAT, paroxysmal atrial tachycardia; SD, standard deviation; NS, no significant difference. 
of the presumed inaccuracies of this method. QRS and QT intervals were also measured and expressed as an average of 10 determinations. The QT interval was corrected for heart rate using the Bazett formula, $\mathrm{QTc}=(\mathrm{QT} / \sqrt{ } \mathrm{RR}) .^{6}$

Plasma procainamide levels were determined spectrophotometrically, using the method of Mark et al., ${ }^{7}$ within one minute of stopping the infusion. All 21 patients had standard M-mode echocardiograms for determination of maximum left atrial diameter at peak ventricular systole measured by the leading edge convention, using a Smith Kline Ekoline 20A ultrasonoscope interfaced with an Irex Continutrace strip chart recorder. Thyroid function studies ( $T_{3}$ uptake and $T_{4}$ RIA) were obtained on all patients.

Variables of age, plasma procainamide level and dose, heart rate, and left atrial diameter were analysed by the unpaired $t$ test; $\chi^{2}$ analysis was used to compare the duration of atrial fibrillation between groups (converters vs non-converters). The paired $t$ test was used to evaluate changes in $Q R S$ and QTc intervals within each group. An interval of $10 \mathrm{~ms}$ was arbitrarily chosen as the threshold of visual accuracy at $25 \mathrm{~mm} / \mathrm{s}$ paper speed. Mean changes less than this value were considered to represent no change.

\section{Results}

Thyroid function was normal in all patients. In six of 21 patients, the cause of the atrial fibrillation could not be ascertained. Nine patients had atherosclerotic heart disease, seven had valvular heart disease, and five had systemic hypertension. Mitral valve disease was significantly more common in nonconverters than in converters $(6 / 12$ vs $0 / 9, \mathrm{p}<0.05)$. The incidence of idiopathic atrial fibrillation, atherosclerotic heart disease, or hypertension was not statistically different between converters and non-converters $(p>0.05)$ (Table 1).

The duration of atrial fibrillation, as well as previous history of palpitation, documented atrial fibrillation, or other supraventricular arrhythmias are recorded in Table 1. All patients fitted the New York Heart Association classes 0, I, or II.

Table 2 Determinants of conversion of atrial fibrillation by procainamide

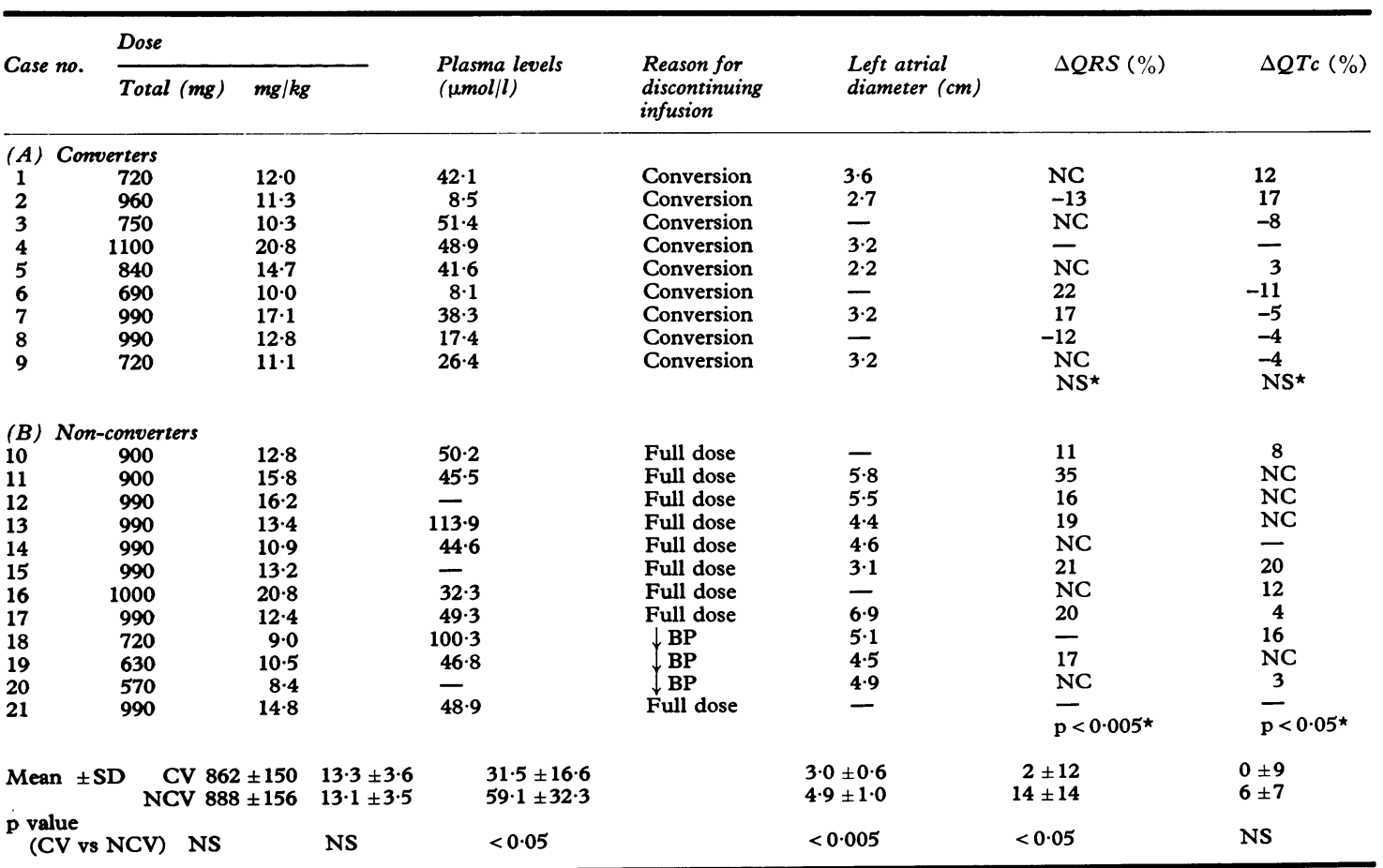

$\triangle$ QRS (\%), per cent change in QRS duration; $\Delta$ QTc (\%), per cent change in corrected QT interval; NC, no change; SD, standard deviation; NS, no significant difference.

* Comparison of mean changes before and after procainamide administration. 
Initial ventricular rates varied between 70 and 170/min; initial blood pressures ranged from $90 / 70$ to $176 / 120 \mathrm{mmHg}$.

Conversion to sinus rhythm occurred in nine patients. Twelve patients did not convert (Table 2). Hypotension necessitating discontinuation of infusion occurred in three non-converters, all of whom recovered spontaneously without specific treatment. The remaining nine patients who failed to convert to sinus rhythm received the maximum dose as defined previously. In the nine converters sinus rhythm was established at a mean dose of 862 $\pm 150 \mathrm{mg}(13.3 \pm 3.6 \mathrm{mg} / \mathrm{kg})$, with a range of 690 to $1100 \mathrm{mg}$, at a mean plasma level of $31.5 \pm 16.6$ $\mu \mathrm{mol} / \mathrm{l}(7 \cdot 4 \pm 3.9 \mu \mathrm{g} / \mathrm{ml})$. There were no significant differences between converters and non-converters with respect to age, initial ventricular rates, initial QRS or QTc intervals, total dose of procainamide, or dose per $\mathrm{kg}$ body weight.

Non-converters achieved significantly higher mean plasma levels of procainamide, $59 \cdot 1 \pm 32 \cdot 3$

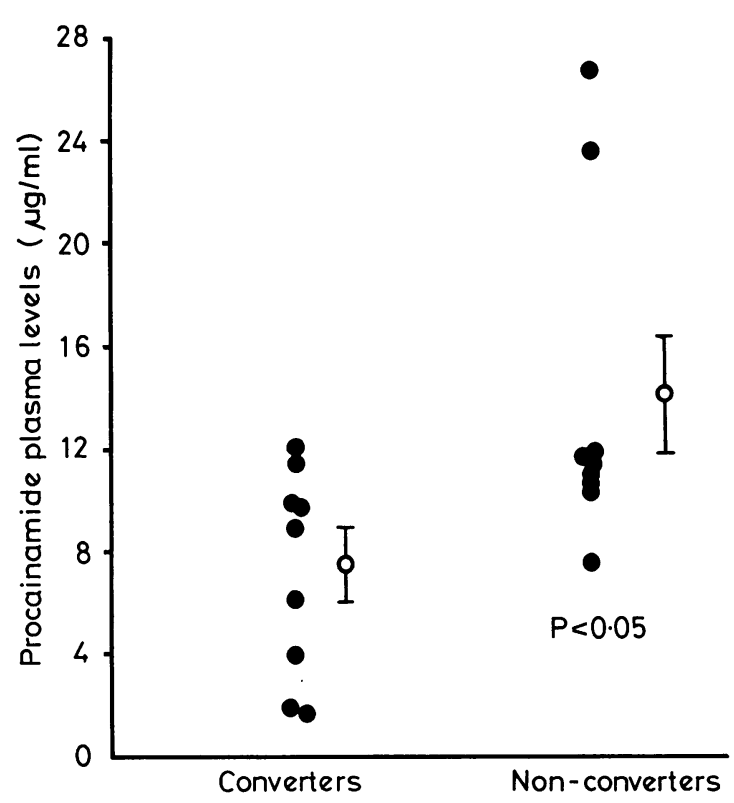

Fig. 1 Relation between procainamide plasma levels and the tendency for conversion of atrial fibrillation to sinus rhythm during intravenous infusion. Closed circles represent plasma values for individual patients at the discontinuation of infusion. Open circles represent mean values with standard errors of means for both subgroups. Patients who did not convert to sinus rhythm had significantly higher plasma levels of the drug. Plasma levels were not available in three non-converters. To convert plasma levels to SI units, ie to $\mu \mathrm{mol} / \mathrm{l}$, multiply by $4 \cdot 25$. $\mu \mathrm{mol} / 1$ versus $31.5 \pm 16.6 \mu \mathrm{mol} / 1 \quad(13.9 \pm 7.6 \mu \mathrm{g} / \mathrm{ml}$ versus $7.4 \pm 3.9 \mu \mathrm{g} / \mathrm{ml}, \mathrm{p}<0.05)$ at similar doses per $\mathrm{kg}(13.1 \pm 3.5 \mathrm{mg} / \mathrm{kg}$ versus $13.3 \pm 3.6 \mathrm{mg} / \mathrm{kg})$ (Fig. 1). Mean QRS and QTc intervals were not altered significantly in converters; these intervals were prolonged significantly, however, in nonconverters $(\mathrm{p}<0.005$ and $\mathrm{p}<0.05$, respectively). The duration of atrial fibrillation and the mean left atrial diameter in converters were significantly less than those of non-converters $(p<0.05$, and $\mathrm{p}<0.005$, respectively) (Table 1 and Fig. 2).

\section{Discussion}

The use of intravenous procainamide for the treatment of both ventricular extrasystoles and supraventricular arrhythmias, including atrial fibrillation, is, of course, not new. ${ }^{7-10}$ The frequency of toxic manifestations, such as depression of cardiac output and blood pressure, vascular collapse, depression of cardiac impulse formation and conduction, prolongation of the QRS and QT intervals, and induction of ventricular arrhythmias precipitated by this route of administration, has been recognised previously. ${ }^{11}$ In most instances, however, toxicity has occurred at infusion rates of $100 \mathrm{mg}$ or more per minute. ${ }^{11-13}$ It is likely that at these high

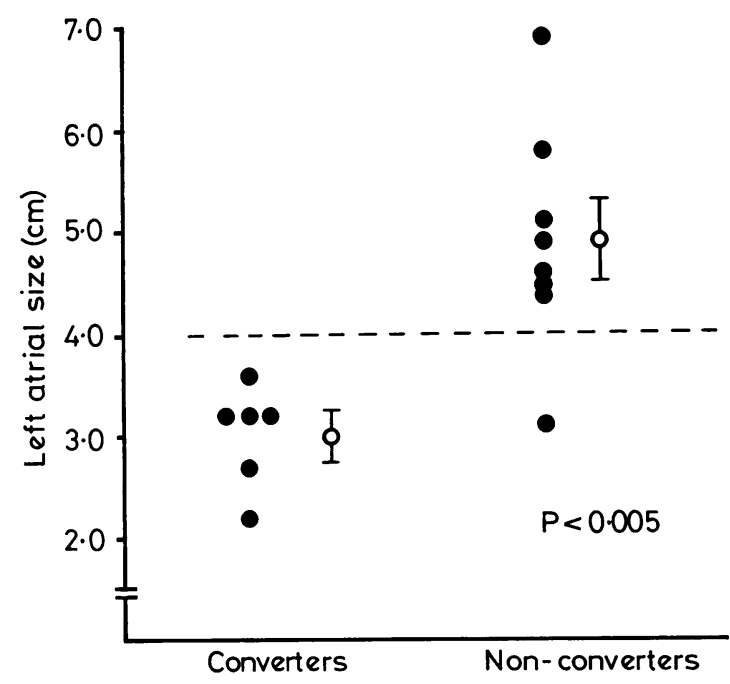

Fig. 2 Relation between left atrial diameter measured by $M$-mode echocardiography and the tendency for conversion of atrial fibrillation to sinus rhythm. Meaning of symbols as in Fig. 1. Note that all patients with normal left atrial dimensions converted, except for one patient in whom atrial fibrillation was present for three months. Left atrial diameters were not obtainable in three patients from each subgroup. 
infusion rates, adequate drug distribution did not take place. ${ }^{14}$ Though toxic manifestations have been reported with infusion rates of $25 \mathrm{mg} / \mathrm{min}$ in patients with acute or suspected myocardial infarction, in only two of $\mathbf{4 2}$ cases was it necessary to discontinue the infusion, and in both cases plasma levels of procainamide were in the therapeutic range..$^{15}$ It is generally accepted, therefore, that infusion rates of 25 to $50 \mathrm{mg}$ per minute are safe and are accompanied by a low incidence of toxicity. ${ }^{11} 16$ Though the presence of significant underlying heart disease also may predispose to toxicity, ${ }^{17} 18$ possibly as a result of altered pharmacokinetics relating to different distribution characteristics, this feature was unlikely to be important in our patients who were in New York Heart Association class II or less.

An infusion rate of $30 \mathrm{mg} / \mathrm{min}$ produced conversion to sinus rhythm in nine patients with normal left atrial diameters at a time when plasma concentrations of procainamide were of the order of $29.7 \mu \mathrm{mol} / 1(7 \mu \mathrm{g} / \mathrm{ml})$; in these patients, no significant alterations in the QRS or QTc intervals were noted. This was in contrast to the patients who did not convert despite higher plasma concentrations of the drug, in whom significant QRS and QTc prolongation were observed $(\mathrm{p}<0.005$ and $\mathrm{p}<0.05$, respectively). The fact that nonconverters had significantly higher plasma levels of procainamide at similar doses per $\mathrm{kg}$ of body weight when compared with converters is unexplained. Such differences, however, are not accounted for readily by differences in volumes of distribution, since the haemodynamic status, determined clinically, was similar in both patient subgroups. Though a majority of the plasma levels achieved in both subgroups was above the recommended therapeutic range for the steady state, all but two levels, 113.9 $\mu \mathrm{mol} / 1(26.8 \mu \mathrm{g} / \mathrm{ml})$ in case 13 and $100.3 \mu \mathrm{mol} / 1$ $(23.6 \mu \mathrm{g} / \mathrm{ml})$ in case 18 , are in agreement with previously reported values for the initial phase of rapid distribution after intravenous administration. ${ }^{13}$

That the mean dose of procainamide required for conversion was greater than the maximum recommended loading dose is not surprising since conversion of atrial arrhythmias has been known to require higher concentrations of procainamide than has conversion of ventricular arrhythmias. ${ }^{19}$ That no patients converted at a dose of $10 \mathrm{mg} / \mathrm{kg}$ or less is surprising, however, and should be borne in mind when attempting to convert atrial fibrillation by this method.

In three of our patients (cases 18, 19, 20), it was necessary to discontinue drug administration at relatively low doses because of hypotension, before conversion to sinus rhythm could be achieved. In these patients hypotension could not be related to excessive drug administration, or to toxic plasma drug levels in one of them (case 19, plasma level $46.8 \mu \mathrm{mol} / 1(11.0 \mu \mathrm{g} / \mathrm{ml}))$. A plasma drug level was not obtained in case 20 because of technical reasons, but in case 18 the procainamide plasma level of $100.3 \mu \mathrm{mol} / \mathrm{l} \quad(23.6 \mu \mathrm{g} / \mathrm{ml})$ and the degree of prolongation of the QTc interval (16\%) were among the highest in the entire series. In these patients, decreases were recorded in both systolic and diastolic blood pressures, suggesting, as has been reported previously, that alterations in blood pressure resulting from procainamide are induced by myocardial depression, ${ }^{11} 1820$ and peripheral vasodilatation. ${ }^{16}$ Alterations in blood pressure were not limited to these three patients, however, and, in fact, most converters manifested modest drops in both systolic and diastolic blood pressures just before conversion; no specific treatment was needed.

The duration of atrial fibrillation and the left atrial diameter are among the determinants of the likelihood for cardioversion by direct current countershock. ${ }^{21}$ Since the tendency for spontaneous return to sinus rhythm also may be related to these variables, might the patients in the present study have converted spontaneously? If so, sinus rhythm would have been as likely as not to have been restored at inappropriately low doses of the drug. In fact, however, every converter required at least $10 \mathrm{mg} / \mathrm{kg}$. In two patients, restoration of sinus rhythm occurred at plasma levels less than $17 \mu \mathrm{mol} / 1$ $(4 \mu \mathrm{g} / \mathrm{ml})$. Though these patients may have converted spontaneously, their elimination from the study group would not have appreciably altered the statistical analysis.

While our data indicate that procainamide is effective in converting atrial fibrillation to sinus rhythm, the mechanism of its action is not clear. As with quinidine, the major electrophysiological action of procainamide is to depress the fast response (class I effect) in cardiac muscle, leading to a lengthening of the effective refractory period. Other class I agents, however, such as lignocaine and mexiletine, which also prolong the effective refractory period in heart muscle, are ineffective in converting atrial fibrillation. Furthermore, it is known that pronounced shortening of the atrial action potential duration after vagal stimulation ${ }^{22}$ or by the induction of thyrotoxicosis, ${ }^{23}$ enhances the tendency to fibrillate. This fact is consistent with the observation that patients who relapse into atrial fibrillation after direct current countershock tend to have shorter atrial action potentials (assessed by intra-atrial suction electrodes) when compared with those who maintain stable sinus rhythm. ${ }^{24}$ In this regard, it is interesting that amiodarone, which has 
a weak class I action but a pronounced tendency to prolong the action potential duration uniformly, ${ }^{25}$ is often effective in restoring and maintaining sinus rhythm in patients with atrial fibrillation. ${ }^{26}$

Both procainamide and quinidine prolong the action potential duration in association with their potent class I actions. This combination of electrophysiological effects may contribute to their useful effects in atrial fibrillation. The fact that the QTc interval (reflecting ventricular repolarisation) was not prolonged by procainamide in patients who converted to sinus rhythm in the present series, does not negate the possibility that atrial repolarisation in these patients was delayed by the drug. Studies involving the measurement of atrial repolarisation time by intracavitary suction electrodes during procainamide conversion of atrial fibrillation will, therefore, be of much theoretical interest.

Whatever the precise mechanism of action of procainamide in converting atrial fibrillation to sinus rhythm, the clinical significance of the present study should be emphasised. Intravenous infusion of procainamide in patients who have no clinical evidence of significant left ventricular dysfunction appears to be effective, safe, and rapidly acting in the conversion to sinus rhythm of acute onset or paroxysmal atrial fibrillation. Potential converters can be identified readily by a history of recent onset atrial fibrillation, and by echocardiographic demonstration of normal left atrial size. Though no patient reverted to atrial fibrillation within 48 hours after conversion, no conclusions can be drawn regarding its long-term efficacy in maintaining sinus rhythm, since different antiarrhythmic drugs were used after conversion.

These results suggest that intravenous procainamide may be infused without a predetermined dose limit and discontinued either with conversion of atrial fibrillation or with the appearance of adverse reactions. This form of treatment may be superior to more conventional methods of conversion currently employed. If echocardiography is not available, we still advocate a trial of procainamide because of its simplicity and low morbidity.

\section{References}

1 Hoffman BF. The action of quinidine and procainamide on single fibres of dog ventricle and specialized conducting systems. Ann Acad Bras Cienc 1958; 29: 365.

2 Bigger JT Jr. Arrhythmias and antiarrhythmic drugs. Adv Intern Med 1972; 18: 251-81.

3 Singh BN. Rational basis of antiarrhythmic therapy: the clinical pharmacology of commonly used antiarrhythmic drugs. Angiology 1978; 29: 206-42.
4 Rosen MR, Hoffman BF. Mechanisms of action of antiarrhythmic drugs. Circ Res 1973; 32: 1-8.

5 Cranefield PF, Wit AL, Hoffman BF. Genesis of cardiac arrhythmias. Circulation 1973; 47: 190-204.

6 Bazett HC. An analysis of the time-relations of electrocardiograms. Heart 1920; 7: 353-70.

7 Mark LC, Kayden HJ, Steele JM, et al. The physiologic disposition and cardiac effects of procaine amide. F Pharmacol Exp Ther 1951; 102: 5-15.

8 McCord MC, Taguchi JT. A study of the effect of procaine amide hydrochloride on supraventricular arrhythmias. Circulation 1951; 4: 387-93.

9 Miller G, Weinberg SL, Pick A. The effect of procaine amide (Pronestyl) in clinical auricular fibrillation and flutter. Circulation 1952; 6: 41-50.

10 Pascale LR, Bernstein LM, Schoolman HM, Foley $\mathrm{EF}$. Intravenous procaine amide in the treatment of cardiac arrhythmias. Am Heart $\mathcal{F} 1954$; 48: 110-22.

11 Bigger JT Jr, Heissenbuttel RH. The use of procaine amide and lidocaine in the treatment of cardiac arrhythmias. Prog Cardiovasc Dis 1969; 11: 515-34.

12 Berry K, Garlett EL, Bellet S. Gefter WI. The use of Pronestyl in the treatment of ectopic rhythms: treatment of 98 episodes in 78 patients. $\mathrm{Am} \mathcal{F} \mathrm{Med}$ $1951 ; 11$ : $431-41$.

13 Koch-Weser J, Klein SW. Procainamide dosage schedules, plasma concentrations, and clinical effects. f AMA 1971; 215: 1454-60.

14 Zapata-Díaz J, Cabrera E, Méndez R. An experimental and clinical study on the effects of procaine amide (Pronestyl) on the heart. Am Heart $\mathcal{F} 1952$; 43: 854-70.

15 Karlsson E. Procainamide and phenytoin: comparative study of their antiarrhythmic effects at apparent therapeutic plasma levels. $B r$ Heart $\mathcal{F} 1975$; 37: 731-40.

16 Koch-Weser J. Clinical application of the pharmacokinetics of procaine amide. Cardiovasc Clin 1974; 63-75.

17 McClendon RL, Hansen WR, Kinsman JM. Hemodynamic changes following procaine amide administered intravenously. Am F Med Sci 1951; 222: 375-81.

18 Harrison DC, Sprouse JH, Morrow AG. The antiarrhythmic properties of lidocaine and procaine amide. Circulation 1963; 28: 486-91.

19 Schaffer AI, Steinman R, Scherf D. Intravenous procaine: its effect on the human electrocardiogram and on cardiac arrhythmias. Cardiologia 1950; 16: 342-53.

20 Giardina EV, Heissenbuttel RH, Bigger JT Jr. Intermittent intravenous procaine amide to treat ventricular arrhythmias. Ann Intern Med 1973; 78: 183-93.

21 Henry WL, Morganroth J, Pearlman AS, et al. Relation between echocardiographically determined left atrial size and atrial fibrillation. Circulation 1976; 53: 275-9.

22 Burn JH. The cause of fibrillation. $\mathrm{Br} M e d \mathcal{F}$ i: $1960 ; 1379-84$.

23 Freedberg AS, Papp JG, Vaughan Williams EM. The effect of altered thyroid state on atrial intracellular 
potentials. f Physiol (Lond) 1970; 207: 357-69.

24 Olsson SB, Cotoi S, Varnauskas E. Monophasic action potential and sinus rhythm stability after conversion of atrial fibrillation. Acta Med Scand 1971; 190: 381-7.

25 Singh BN, Vaughan Williams EM. The effect of amiodarone, a new anti-anginal drug, on cardiac muscle. Br f Pharmacol 1970; 39: 657-67.

26 Olsson SB, Brorson L, Varnauskas E. Class 3 antiarrhythmic action in man. Observations from monophasic action potential recordings and amiodarone treatment. Br Heart $\mathcal{f}$ 1973; 35: 1255-9.

Requests for reprints to Publications Office, Division of Cardiology, Cedars-Sinai Medical Center, 8700 Beverly Boulevard, Los Angeles, California 90048, USA. 